\title{
Pós-colheita de abacates 'Fuerte' e 'Hass': características físicas e químicas, danos e controle de doenças
}

\section{Postharvest of 'Fuerte' and 'Hass' avocados: physical and chemical characteristics, damages and control of diseases}

\author{
Ivan Herman Fischer ${ }^{1 *}$; Hugo José Tozze Júnior²; \\ Maria Cecília de Arruda ${ }^{3}$; Nelson Sidnei Massola Júnior ${ }^{4}$
}

\begin{abstract}
Resumo
Doença pós-colheita é considerada uma importante causa de desvalorização do abacate por ocasião da comercialização. Este trabalho objetivou avaliar os danos pós-colheita e as características físicas e químicas de abacates 'Fuerte' e 'Hass', beneficiados em packinghouse, e o efeito de produtos no controle pós-colheita das podridões. As características cor da casca, firmeza, acidez titulável e sólidos solúveis e a incidência dos danos pós-colheita foram avaliadas periodicamente, em abacates amostrados em três etapas do beneficiamento (chegada, beneficiados no palete e beneficiados após armazenamento a $5^{\circ} \mathrm{C}$ por 30 dias). Para o controle das doenças testou-se por imersão os seguintes produtos: azoxistrobina, cloreto de benzalcônio, dióxido de cloro, Ecolife ${ }^{\circledR}$, hipoclorito de sódio, imazalil, procloraz e tiabendazol. Em geral, as maiores alterações físicas e químicas foram observadas nos frutos amostrados na chegada ao packinghouse e nos frutos beneficiados, armazenados por 30 dias. A ocorrência de podridões foi de 56,7\% em abacate 'Fuerte' e de 75,7\% em 'Hass' aos 15 dias de armazenamento a $25^{\circ} \mathrm{C}$. Menor incidência de podridões foi observada nos frutos do palete e uma maior incidência nos frutos beneficiados, após armazenamento refrigerado. A antracnose foi a principal doença nas duas cultivares. As injúrias mecânicas foram crescentes com o beneficiamento, entretanto, não influenciaram no aparecimento das podridões. Os fungicidas procloraz e imazalil foram os mais eficientes em reduzir a incidência das podridões.
\end{abstract}

Palavras-chave: Persea americana, qualidade, podridões, Colletotrichum, defensivos

\begin{abstract}
Postharvest disease is considered an important cause of avocado depreciation during its commercialization. This work aimed to evaluate the postharvest damages and the physical chemical characteristics of avocados 'Fuerte' and 'Hass', processed at the packinghouse, and to evaluate the effect of products for postharvest disease control. The characteristics skin color, firmness, titratable acidity and soluble solids content and the incidence of the postharvest damages were evaluated periodically in avocados sampled in three different stages in a packinghouse (arrival, pallet and processed fruits after storage for 30 days at $5^{\circ} \mathrm{C}$ ). For diseases control, 'Hass' avocado were treated by immersion with the following products: azoxystrobin, benzalkonium chloride, chlorine dioxide, Ecolife ${ }^{\circledR}$, sodium hypochlorite, imazalil, prochloraz and thiabendazole. In general, the highest physical chemical changes were observed in fruits
\end{abstract}

\footnotetext{
${ }^{1}$ Eng $^{\mathrm{o}}$ Agr $^{\mathrm{o}}$, Dr. em Fitossanidade, Agência Paulista de Tecnologia dos Agronegócios, APTA Centro Oeste - Bauru, SP. E-mail: ihfische@apta.sp.gov.br

${ }^{2}$ Eng. Agr,. Bolsista do CNPq, Doutorando em Fitopatologia da ESALQ/USP, Piracicaba, SP. E-mail: htozze@gmail.com

3 Eng $^{\mathrm{o}} \mathrm{Agr}^{\mathrm{o}}, \mathrm{Dr}^{\mathrm{a}}$ em Fitotecnia, APTA Centro Oeste, Bauru, SP. E-mail: mcarruda@apta.sp.gov.br

${ }^{4}$ Prof. Dr. do Depto. de Fitopatologia e Nematologia da ESALQ/USP, Piracicaba, SP. Bolsista de Produtividade em Pesquisa do CNPq. E-mail: nmassola@esalq.usp.br

* Autor para correspondência
} 
collected at their arrival to the packinghouse and in processed fruits after stored for 30 days at 15 days of storage at $25^{\circ} \mathrm{C}$. The rots incidence was $56,7 \%$ in 'Fuerte' and $75,7 \%$ in 'Hass'. Lower incidence of rots was observed in fruits sampled at the pallet and a higher incidence in the processed fruits, after refrigerated storage. Anthracnose was the most important disease in both cultivars. The mechanical injuries increased with the processing stages; however, they did not influence the incidence of the rots. Procloraz and imazalil were the most efficient fungicides in reducing the incidence of rots.

Key words: Persea americana, quality, rots, Colletotrichum, pesticides

\section{Introdução}

O abacateiro (Persea americana) é uma fruteira tropical originária do continente americano, tendo o México e a Guatemala como centros de diversidade (DONADIO, 1995). As variedades de abacate preferidas para consumo no Brasil geralmente apresentam baixo teor de óleo e frutos grandes. Para exportação, as variedades mais cultivadas são a Hass e a Fuerte, conhecidas popularmente como 'avocado', de tamanho pequeno e alto teor de óleo. A casca do abacate 'Hass' é grossa, rugosa e verde, na planta e imediatamente após a colheita, mas com o amadurecimento a casca muda para um marrom escuro. Enquanto o abacate 'Fuerte' possui casca mais lisa, fina, sem brilho e verde, não escurecendo com o amadurecimento (DONADIO, 1995). OBrasil é o quinto produtor mundial de abacate e São Paulo, o principal Estado produtor com aproximadamente 77 mil toneladas (AGRINUAL, 2008).

Os danos (redução na qualidade ou quantidade de um produto) pós-colheita podem ser de natureza física, fisiológica e patológica e se expressam desde a colheita até seu uso pelo consumidor. Diversas doenças ocorrem ou manifestam-se tanto em pré como em pós-colheita do abacate. A antracnose, causada por Colletotrichum gloesporioides e $C$. acutatum, ocorre em todos os países produtores de abacate, sendo considerada uma das mais importantes doenças (PRUSKY; KEEN; EAKS, 1983; PEGG et al., 2002; QUEZADA; ROJAS; TELIZ, 2007). A antracnose afeta principalmente frutos, com sintomas iniciando-se por pontuações de coloração escura e formato circular, que evoluem atingindo parte do fruto ou necrosando-o completamente. As necroses ultrapassam a casca e alcançam a polpa do fruto (PICCININ;
PASCHOLATI; DI PIERO, 2005). Levantamentos da incidência de podridões em abacate 'Hass', no mercado varejista da Austrália, detectaram 41\% dos frutos com podridões em níveis inaceitáveis, sendo 25\% decorrentes da antracnose (LEDGER et al., 1993). As variedades guatemalenses são menos suscetíveis à antracnose, enquanto a variedade Fuerte, um híbrido de guatemalense e mexicana, é bastante afetada (PICCININ; PASCHOLATI; DI PIERO, 2005).

Além da podridão de frutos ocasionada por Colletotrichum spp., outros patógenos podem afetar os frutos em pós-colheita, como Dothiorella gregaria, Lasiodiplodia theobromae, Hersonia sp., Rhizopus nigricans, Pestalotiopsis versicolor, Fusarium spp., Alternaria spp., Fusicoccum spp. e Phomopsis spp. (PEGG et al., 2002). Algumas destas doenças, como as podridões de Dothiorella e de Lasiodiplodia podem ser confundidas com a antracnose ou mesmo ocorrerem em associação (DARVAS, 1978). No entanto, até o momento não foram conduzidos trabalhos a fim de avaliar os danos causados por estes patógenos, assim como verificar a ocorrência ou não de demais espécies em condições brasileiras.

O controle das doenças pós-colheita baseiase em adubações equilibradas do pomar; podas de limpeza, com a eliminação de frutos com podridões; e pulverização de fungicidas no pomar, no período compreendido entre o florescimento e a frutificação (COATES et al., 2001; PICCININ; PASCHOLATI; DI PIERO, 2005). Entretanto, é muito difícil obter frutos livres da antracnose, mesmo após rigorosa aplicação dos fungicidas recomendados (MCMILLAN JUNIOR, 1971; 
KOTZÉ; KUSCHKE, 1979; DARVAS, 1981). Ferimentos nos frutos e choques capazes de provocar amassamentos devem ser evitados através de cuidados durante as operações de colheita e pós-colheita, como a manutenção do pedúnculo. Doenças, como a verrugose e a cercosporiose, estão associadas à penetração de Colletotrichum spp. e também devem ser manejadas (PALMATEER; PLOETZ; HARMON, 2006).

Em pós-colheita, recomenda-se o acondicionamento refrigerado $\left(4-7^{\circ} \mathrm{C}\right)$, onde ocorre o atraso no desenvolvimento das podridões (PEGG et al., 2002). Os fungicidas estrobilurina e procloraz são eficientes em pós-colheita (EVERETT; KORSTEN, 1998; COATES et al., 2001). Entretanto, decorrente das crescentes restrições ao uso de certos fungicidas em pós-colheita, alguns países não permitem o tratamento pós-colheita com procloraz (PEGG et al., 2002). A aplicação de cera melhora a aparência e aumenta o período de conservação do fruto, através da diminuição da taxa transpiratória e da atividade metabólica (DARVAS; KOTZE; WEHNER, 1990). No Brasil, abacates destinados ao mercado externo são rotineiramente encerados, mas não recebem tratamento químico pós-colheita.

Os objetivos deste trabalho foram avaliar os danos pós-colheita e as características físicas e químicas de abacates 'Fuerte' e 'Hass', beneficiados em packinghouse de Bauru-SP, bem como avaliar o efeito de produtos no controle pós-colheita das doenças do abacate 'Hass'.

\section{Material e Métodos}

\section{Local de execução dos experimentos}

Amostragens dos frutos para avaliação física e química e de danos pós-colheita foram realizadas concomitantemente em fevereiro e março de 2008 para o abacate 'Fuerte' e em junho e julho de 2008 para 'Hass', em packinghouse de BauruSP que exporta aproximadamente $80 \%$ do volume beneficiado para a Europa, Argentina e Canadá. As amostras de abacate 'Fuerte' foram procedentes de uma fazenda de Bauru-SP e as de abacate 'Hass' de Olímpia e Bernardino de Campos-SP. A avaliação de produtos no controle pós-colheita das doenças de abacate 'Hass' foi realizada em agosto e setembro de 2008 com frutos procedentes de Bernardino de Campos.

Os ensaios de avaliação física e química e dos danos pós-colheita foram realizados no laboratório da Agência Paulista de Tecnologia dos Agronegócios, em Bauru, e os ensaios de controle pós-colheita das podridões de abacate 'Hass' foram realizados no laboratório de micologia da ESALQ/ USP, em Piracicaba - SP.

\section{Avaliação dos danos pós-colheita}

Cinquenta frutos foram coletados por amostragem em cada uma das seguintes etapas do beneficiamento em packinghouse: 1) chegada nos engradados plásticos de chegada dos frutos; 2) palete - em caixas de papelão do palete, após tratamento por imersão com procloraz $\left(1000 \mathrm{mg} \mathrm{L}^{-1}\right)$ (apenas abacate 'Fuerte'), aparação dos pedúnculos e seleção manual dos frutos injuriados, aplicação de cera e classificação automatizada por massa (g); e 3) câmara - frutos beneficiados (etapa 2), após o período de 30 dias de armazenamento refrigerado a $5^{\circ} \mathrm{C}$

Os frutos foram individualizados em bandejas plásticas e submetidos à câmara úmida por 24 horas, visando favorecer a ocorrência de podridões, permanecendo por mais 14 dias a $25^{\circ} \mathrm{C}$ e $70-75 \%$ de umidade relativa. A incidência de doenças e danos mecânicos foi avaliada visualmente após a retirada da câmara úmida e a cada dois ou três dias. Os fungos isolados de frutos com podridões tiveram a patogenicidade confirmada através da inoculação em frutos sadios.

Compararam-se as incidências dos danos póscolheita nas diferentes etapas do beneficiamento por meio de teste não paramétrico de comparação de múltiplas proporções, ao nível de $5 \%$ de probabilidade (ZAR, 1999). 


\section{Avaliação fisica e química}

Vinte e sete frutos amostrados em cada uma das três etapas do beneficiamento em packinghouse foram utilizados para avaliação das seguintes variáveis: a) firmeza, determinada com penetrômetro modelo FT 327, com ponteira de $8 \mathrm{~mm}$, na região equatorial e expressa em $\mathrm{kg}$; b) teor de sólidos solúveis, determinado em refratômetro digital Atago, modelo PAL-1, e os resultados expressos em ${ }^{\circ}$ Brix; d) teor de acidez titulável, determinado por titulação com $\mathrm{NaOH}$ até $\mathrm{pH} 8,1$ e expresso em $\%$ de ácido cítrico; d) cor da casca, determinada usando-se colorímetro Minolta, modelo CR-400 e resultados expressos em ângulo de cor $\left({ }^{\circ} \mathrm{h}\right)$. Os frutos foram submetidos a $25^{\circ} \mathrm{C}$ por 10 ('Hass') ou 21 dias ('Fuerte'), sendo as análises realizadas em intervalos de sete dias e ao final do período de armazenamento, com três repetições de três frutos para cada tratamento.

Os resultados obtidos das análises físicas e químicas foram submetidos à análise de variância e as médias foram comparadas durante o armazenamento e entre as etapas de beneficiamento pelo teste de Tukey (5\%). As mudanças nas características físicas e químicas foram correlacionadas com a incidência de podridões, testando-se correlações simples a 5\% de probabilidade.

\section{Controle pós-colheita de podridões}

Frutos de abacate 'Hass' foram colhidos, uniformizados quanto à ausência de defeitos, lavados com detergente neutro e imersos por 30 segundos em suspensão contendo os seguintes defensivos ou sanitizantes (doses em mg ou $\mu$ L.L1): água (testemunha), azoxistrobina (75), cloreto de benzalcônio (1000), dióxido de cloro (150 de cloro ativo), Ecolife ${ }^{\circledR}$ (4000), hipoclorito de sódio (150 de cloro ativo), imazalil (1000), procloraz (1000) e tiabendazol (1000).

Após a aplicação dos tratamentos e secagem dos frutos, estes foram submetidos à câmara úmida por
24 horas a $25^{\circ} \mathrm{C}$ e armazenados a mesma temperatura por mais 13 dias, sendo avaliados quanto à incidência de sintomas das doenças pós-colheita a cada dois dias. $\mathrm{O}$ delineamento experimental foi o inteiramente ao acaso com nove tratamentos e 20 frutos por tratamento. O experimento foi repetido uma vez. Diferenças entre os tratamentos foram verificadas pelo teste não paramétrico de comparação de múltiplas proporções, em nível de 5\% (ZAR, 1999).

\section{Resultados e Discussão}

Avaliação dos danos pós-colheita

A incidência total de podridões em abacates 'Fuerte' e 'Hass' diferiram estatisticamente entre as etapas de beneficiamento, ao final dos 15 dias de armazenamento a $25^{\circ} \mathrm{C}$ e $70-75 \%$ de UR. Observouse redução da incidência total de podridões nos frutos amostrados no palete em relação aos da chegada e um aumento da incidência nos frutos beneficiados que permaneceram na câmara a $5^{\circ} \mathrm{C}$ por 30 dias (Tabela 1). Segundo Hopkirk, White e Beever (1994), após armazenamento refrigerado o abacate 'Hass' deve ser amadurecido a $15^{\circ} \mathrm{C}$, pois a $25^{\circ} \mathrm{C}$, como empregado neste trabalho, a qualidade final do fruto é afetada. A antracnose foi a principal doença pós-colheita com incidência média de 45,7\% em abacate 'Fuerte' e 68,7\% em abacate 'Hass'. Incidência superior a 90\% de antracnose foi observada em abacate 'Hass', cultivado sob condições favoráveis a doença na Austrália (WILLINGHAM et al., 2006). Na África do Sul, constatou-se $44 \%$ de podridões em abacate, sendo a antracnose responsável por $66 \%$ do total (BEZUIDENHOUT; KUSCHKE, 1983).

Diferenças na incidência de antracnose entre as etapas de beneficiamento foram verificadas a partir do quarto dia de armazenamento a $25^{\circ} \mathrm{C}$, com uma maior incidência nos frutos submetidos a câmara fria (Figura 1). Maior incidência de antracnose nos frutos da chegada em relação aos do palete foi observada a partir do $11^{\circ}$ dia de armazenamento 
para 'Hass' e $13^{\circ}$ dia para 'Fuerte'. A infecção por Colletotrichum spp. ocorre no campo em qualquer estádio do desenvolvimento do fruto e permanece quiescente até o amadurecimento, de modo que os frutos podem ser colhidos aparentemente sadios e manifestarem os sintomas da doença apenas durante o armazenamento e comercialização, quando os níveis de compostos antifúngicos, principalmente o diene, caem (PRUSKY; KEEN; EAKS, 1983).

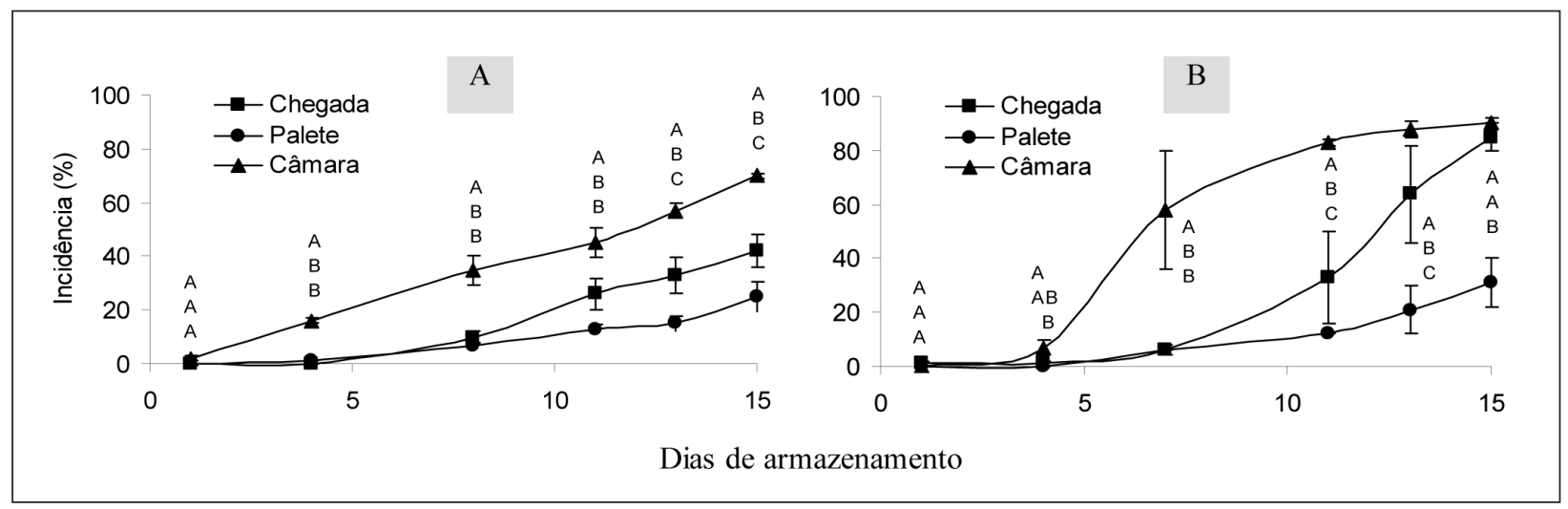

Figura 1. Progresso da Incidência (\%) de antracnose em abacates 'Fuerte' (A) e 'Hass' (B) durante 15 dias de armazenamento a $25^{\circ} \mathrm{C}$.

Com menores incidências médias foram observadas a podridão de fusicocum, atingindo $7 \%$ em abacate 'Fuerte' e 3\% em abacate 'Hass' e a podridão de lasiodiplodia, atingindo $4 \%$ nas duas cultivares, aos 15 dias de armazenamento a $25^{\circ} \mathrm{C}$ (Tabela 1). Diferenças na incidência destas podridões entre as etapas de beneficiamento foram observadas em abacate 'Hass', com maior incidência no palete. Estas podridões são comuns na maioria das regiões produtoras de abacate, mas são geralmente menos importantes que a antracnose (PEGG et al., 2002). Colletotrichum spp. caracterizou-se por uma esporulação alaranjada na superfície do fruto, em contraste com o micélio cinza de Fusicoccum spp.

\section{e L. theobromae.}

As injúrias de batida e lesão não cicatrizada foram crescentes com o beneficiamento dos abacates 'Fuerte' e 'Hass' (Tabela 2). Do total de aumento das injúrias não cicatrizadas observadas em abacates 'Fuerte' e 'Hass', amostrados no palete, 52,2 e $74,4 \%$, respectivamente, foram decorrentes do processo de aparação manual do pedúnculo, com tesoura. Lesões cicatrizadas, decorrentes do atrito das folhas com os frutos foram decrescentes nas duas cultivares, assim como lesões de verrugose (Sphaceloma persea) em abacate 'Fuerte', evidenciando rigorosa seleção manual para estes defeitos que depreciam a aparência dos frutos. Sintomas de cercosporiose (Cercospora purpurea) foram observados em menor frequência nos frutos (2-5\%), não havendo diferenças significativas entre as etapas amostradas. 
Tabela 1. Incidência (\%) ${ }^{1}$ de doenças pós-colheita em abacates 'Fuerte' e 'Hass' oriundos de diferentes etapas do beneficiamento em packinghouse aos 15 dias de armazenamento a $25^{\circ} \mathrm{C}$.

\begin{tabular}{|c|c|c|c|c|c|c|c|c|}
\hline \multirow[t]{2}{*}{ Doenças } & \multicolumn{4}{|c|}{ Abacate 'Fuerte' - Etapas do beneficiamento } & \multicolumn{4}{|c|}{ Abacate 'Hass' - Etapas do beneficiamento } \\
\hline & Chegada & Palete & Câmara & Média & Chegada & Palete & Câmara & Média \\
\hline Antracnose & $42,0 \mathrm{bA}^{2}$ & $25,0 \mathrm{cA}$ & $70,0 \mathrm{aA}$ & $45,7 \mathrm{~A}$ & $85,0 \mathrm{aA}$ & $31,0 \mathrm{bA}$ & $90,0 \mathrm{aA}$ & $68,7 \mathrm{~A}$ \\
\hline Podridão de fusicocum & $8,0 \mathrm{aB}$ & $3,0 \mathrm{aB}$ & $10,0 \mathrm{aB}$ & $7,0 \mathrm{~B}$ & $1,0 \mathrm{bB}$ & $6,0 \mathrm{aB}$ & $2,0 \mathrm{abB}$ & $3,0 \mathrm{~B}$ \\
\hline Podridão de lasiodiplodia & $3,0 \mathrm{aB}$ & $2,0 \mathrm{aB}$ & $7,0 \mathrm{aB}$ & $4,0 \mathrm{~B}$ & $1,0 \mathrm{bB}$ & $10,0 \mathrm{aB}$ & $1,0 \mathrm{bB}$ & $4,0 \mathrm{~B}$ \\
\hline Total & $53,0 \mathrm{~b}$ & $30,0 \mathrm{c}$ & $87,0 \mathrm{a}$ & 56,7 & $87,0 \mathrm{a}$ & $47,0 \mathrm{~b}$ & $93,0 \mathrm{a}$ & 75,7 \\
\hline
\end{tabular}

${ }^{1}$ Média de duas amostragens de 50 frutos, procedentes de Bauru ('Fuerte'), Olímpia ('Hass') e Bernardino dos Campos, SP ('Hass').

${ }^{2}$ Valores seguidos pela mesma letra, minúscula na linha e maiúscula na coluna, não diferem entre si para cada cultivar, em nível de $5 \%$ pelo teste não paramétrico de comparação de múltiplas proporções.

Tabela 2. Incidência (\%) ${ }^{1}$ de injúrias em abacates 'Fuerte' e 'Hass', antes e após o beneficiamento em packinghouse.

\begin{tabular}{lcccc}
\hline \multirow{2}{*}{ Injúrias } & \multicolumn{2}{c}{ Etapas do beneficiamento-Fuerte } & \multicolumn{2}{c}{ Etapas do beneficiamento-Hass } \\
\cline { 2 - 5 } & Chegada & Palete & Chegada & Palete \\
\hline Batida & $9 \mathrm{~b}^{2}$ & $52 \mathrm{a}$ & $6 \mathrm{~b}$ & $24 \mathrm{a}$ \\
Lesão não cicatrizada & $20 \mathrm{~b}$ & $43 \mathrm{a}$ & $19 \mathrm{~b}$ & $58 \mathrm{a}$ \\
Lesão cicatriz. $\left(>1<2 \mathrm{~cm}^{2}\right)$ & $49 \mathrm{a}$ & $20 \mathrm{~b}$ & $28 \mathrm{a}$ & $32 \mathrm{a}$ \\
Lesão cicatrizada $\left(>2 \mathrm{~cm}^{2}\right)$ & $5 \mathrm{a}$ & $0 \mathrm{~b}$ & $9 \mathrm{a}$ & $2 \mathrm{~b}$ \\
Verrugose & $60 \mathrm{a}$ & $32 \mathrm{~b}$ & $28 \mathrm{a}$ & $20 \mathrm{a}$ \\
Cercosporiose & $4 \mathrm{a}$ & $2 \mathrm{a}$ & $5 \mathrm{a}$ & $2 \mathrm{a}$ \\
\hline
\end{tabular}

${ }^{1}$ Média de duas amostragens de 50 frutos, procedentes de Bauru ('Fuerte'), Olímpia ('Hass') e Bernardino de Campos-SP ('Hass'). ${ }^{2}$ Valores seguidos pela mesma letra minúscula na linha não diferem entre si para cada cultivar, em nível de $5 \%$ pelo teste não paramétrico de comparação de múltiplas proporções.

O aumento na incidência de injúrias mecânicas (batida e lesão não cicatrizada) com o beneficiamento não influenciou a ocorrência de podridões, sendo, entretanto, observada diminuição no total de podridões nos frutos do palete, resultado que diverge de Palmateer, Ploetz e Harmon (2006) que atribuem aos ferimentos a favorabilidade do processo infectivo de Colletotrichum em abacate. A menor ocorrência de podridões nos abacates amostrados no palete está possivelmente relacionada com a aplicação de procloraz em abacate 'Fuerte' e também a aplicação de cera de carnaúba, que confere proteção aos frutos e retarda o processo de amadurecimento (DARVAS; KOTZE; WEHNER, 1990), consequentemente atrasando o desenvolvimento dos patógenos quiescentes. Powell (1988) testou ceras, com e sem o fungicida procloraz, no tratamento pós-colheita de abacates e verificou que a antracnose foi severamente reduzida no tratamento com cera, principalmente quando essa foi associada ao fungicida. Em adição, o fato de a infecção ocorrer ainda no campo (PRUSKY; KEEN; EAKS, 1983) ajuda a explicar a ausência de correlação entre as podridões e injúrias mecânicas. Assim, em pós-colheita, não ocorreram novas infecções, mas o desenvolvimento das quiescentes. Outro fator a ser considerado na redução da antracnose com o beneficiamento foi a retirada de frutos com verrugose pelo processo de seleção manual. Segundo Palmateer, Ploetz e Harmon (2006) as lesões de verrugose favorecem a entrada de Colletotrichum spp. nos frutos.

\section{Avaliação física e química}

Os teores médios de sólidos solúveis de abacate 'Fuerte' não foram afetados pelo tempo de armazenamento a $25^{\circ} \mathrm{C}$ e nem pelas etapas do 
beneficiamento (Figura 2A), enquanto em abacate 'Hass', maiores teores de sólidos solúveis $(\mathrm{p}<0,05)$ foram observados nos frutos que permaneceram 30 dias na câmara fria $\left(5^{\circ} \mathrm{C}\right)$ (Figura $\left.2 \mathrm{E}\right)$. Observouse aumento significativo nos teores de sólidos solúveis de abacates 'Hass' amostrados na chegada e no palete no $10^{\circ}$ dia de armazenamento. Os frutos oriundos da câmara não foram analisados no $10^{\circ}$ dia, pois apresentavam-se impróprios para o consumo, com sintomas internos de podridão. Maior período de armazenamento de abacate 'Fuerte' em relação ao abacate 'Hass' deve-se, segundo Ahmed et al. (2007), a menor taxa respiratória observada em 'Fuerte'.

O amadurecimento em abacates está diretamente relacionado, entre outros fatores, ao aumento no conteúdo de óleo, cuja produção consome carboidratos, principalmente os solúveis (BERTILING et al., 2003, citados por SANCHES; DURIGAN; DURIGAN, 2008). No entanto, um fator que eventualmente pode explicar a manutenção e o aumento de sólidos durante o armazenamento, é que a degradação de polissacarídeos tenha liberado hexoses em níveis semelhantes (no caso da manutenção dos teores) ou superiores (no caso do aumento dos teores) ao consumo de açúcares pelos abacates na respiração e na produção de óleo. Além disso, outro fator que pode ter contribuído para o aumento de sólidos solúveis é a perda de massa, a qual pode ter contribuído para concentrar os açúcares (CHITARRA; CHITARRA, 1990). Abacates 'Hass' beneficiados que permaneceram por 30 dias a $5^{\circ} \mathrm{C}$ perderam em média $5,4 \%$ de massa fresca e frutos beneficiados, armazenados por 10 dias a $25^{\circ} \mathrm{C}$, perderam em média $4,2 \%$ de massa fresca (dados não apresentados).

Com relação aos teores de acidez titulável observou-se que os frutos 'Fuerte' da chegada e do palete apresentaram aumento significativo desta variável com o armazenamento a $25^{\circ} \mathrm{C}$ (Figura 2B). Oliveira et al. (2000) também observaram decréscimo do $\mathrm{pH}$ em abacates 'Fuerte' no $4^{\circ}$ dia de armazenamento a $25^{\circ} \mathrm{C}$, o que indica um aumento da acidez. Após a retirada dos frutos beneficiados da câmara fria, observou-se que os mesmos apresentavam teores de acidez semelhantes aos dos frutos amostrados na chegada e no palete e que durante o armazenamento destes frutos a $25^{\circ} \mathrm{C}$ houve manutenção dos teores de acidez. Em relação ao abacate 'Hass' (Figura 2F) não houve mudança significativa dos teores de acidez entre os frutos das diferentes etapas do beneficiamento até o sétimo dia de armazenamento. No $10^{\circ}$ dia de armazenamento observou-se um aumento de acidez titulável dos frutos amostrados na chegada e no palete.

Durante o amadurecimento a coloração da casca do abacate 'Hass' muda de verde para marromescuro (COX et al., 2004), enquanto a coloração da casca do abacate 'Fuerte' apresenta uma redução na intensidade da coloração verde. $O$ ângulo de cor define a coloração básica, onde $0^{\circ}=$ vermelho, $90^{\circ}=$ amarelo e $180^{\circ}=$ verde (MCGUIRE, 1992).

Em abacate 'Fuerte' houve apenas efeito do tempo de armazenamento, com redução média do ângulo de cor $\left({ }^{\circ} \mathrm{h}\right)$ de 121,81 para 114,61 , após 21 dias de armazenamento a $25^{\circ} \mathrm{C}$ (Figura 2C). Frutos de abacate 'Hass' da chegada e da câmara apresentaram redução significativa do ângulo de cor $\left({ }^{\circ} \mathrm{h}\right)$ após sete dias de armazenamento a $25^{\circ} \mathrm{C}$ e um menor ângulo de cor $\left({ }^{\circ} \mathrm{h}\right)$ em relação aos frutos do palete (Figura 2G). A manutenção da coloração dos frutos do palete evidencia a eficiência da aplicação de cera no retardo do processo de amadurecimento. Apenas no $10^{\circ}$ dia observou-se redução significativa do ângulo de cor desses abacates (Figura 2G).

Com relação à firmeza da polpa, observou-se diferença significativa entre a firmeza nos frutos 'Fuerte' amostrados na chegada e no palete, a partir do $14^{\circ}$ dia de armazenamento a $25^{\circ} \mathrm{C}$, evidenciando o efeito da cera na manutenção da firmeza (Figura 2D). Maftoonazad et al. (2007) também observaram maior firmeza em abacates 'Hass' tratados com cera a base de pectina.

A firmeza da polpa é determinada pela força de coesão entre as pectinas. Com o amadurecimento do 
abacate ocorre atuação de enzimas pectinolíticas, particularmente a celulase, a poligalacturonase e a pectinametilesterase, que transformam a pectina insolúvel em solúvel e promovem o amolecimento dos frutos (BOWER; CUTTING, 1988; SEYMOUR; TUCKER, 1993 citados por KLUGE et al., 2002). A modificação da atmosfera gasosa criada pela aplicação de cera reduz a atividade destas enzimas e promove a retenção da firmeza dos frutos durante o armazenamento (MAFTOONAZAD et al., 2007). Quando os frutos foram retirados da câmara (após o armazenamento a $5^{\circ} \mathrm{C}$ por 30 dias) apresentaram firmeza significativamente menor do que os frutos amostrados na chegada e no palete, no início do armazenamento. Os frutos amostrados na câmara apresentaram redução significativa da firmeza uma semana após o armazenamento a $25^{\circ} \mathrm{C}$.

Em relação à firmeza dos frutos 'Hass' amostrados na chegada e dos frutos amostrados no palete observa-se comportamento semelhante aos frutos 'Fuerte', porém a diferença entre a firmeza destes frutos foi observada no $7^{\circ}$ dia de armazenamento. Quanto aos frutos amostrados na câmara o comportamento também foi semelhante aos frutos 'Fuerte' (Figura 2D e H).

Não foram observadas correlações $(p<0,05)$ entre o total de podridões nos frutos de abacate 'Fuerte' e 'Hass' e as alterações nos atributos sólidos solúveis, acidez titulável, cor da casca e firmeza, ao final do período de armazenamento (valores de "r" não apresentados). Embora associações entre o aumento das infecções com mudanças em atributos físico-químicas tenham sido relatadas em cereja (NORTHOVER; BIGGS, 1990), maçã (SHARMA; KAUL, 1988) e pêssego (SOUZA, 2007), essas características não auxiliaram no entendimento das causas de resistência/suscetibilidade do abacate. Assim como no presente estudo, não foram observadas correlações entre a incidência de podridões em frutos cítricos com os parâmetros sólidos solúveis e acidez titulável (FISCHER, 2007).

\section{Controle pós-colheita de podridões}

O fungicida procloraz foi o único produto que reduziu significativamente a antracnose em abacate 'Hass' até o $14^{\circ}$ dia de armazenamento, com $10,8 \%$ de incidência (Tabela 3). Ausência de sintomas de antracnose foi observada até o oitavo dia de armazenamento com os fungicidas procloraz e imazalil, comparado a $13,3 \%$ de incidência na testemunha. Eficácia de procloraz no controle póscolheita de antracnose já havia sido relatado por Powell (1988), Everett e Korsten (1998) e Coates et al. (2001). Controle da doença também foi verificado com cloreto de benzalcônio, dióxido de cloro e tiabendazol, no décimo dia de armazenamento, entretanto, assim como os tratamentos com azoxistrobina, Ecolife ${ }^{\circledR}$ e hipoclorito de sódio, não foram eficientes em reduzir a incidência da antracnose, nas avaliações subsequentes. Aineficácia no controle da antracnose com azoxistrobina diverge dos resultados satisfatórios obtidos por Coates et al. (2001) também em abacate 'Hass'. 

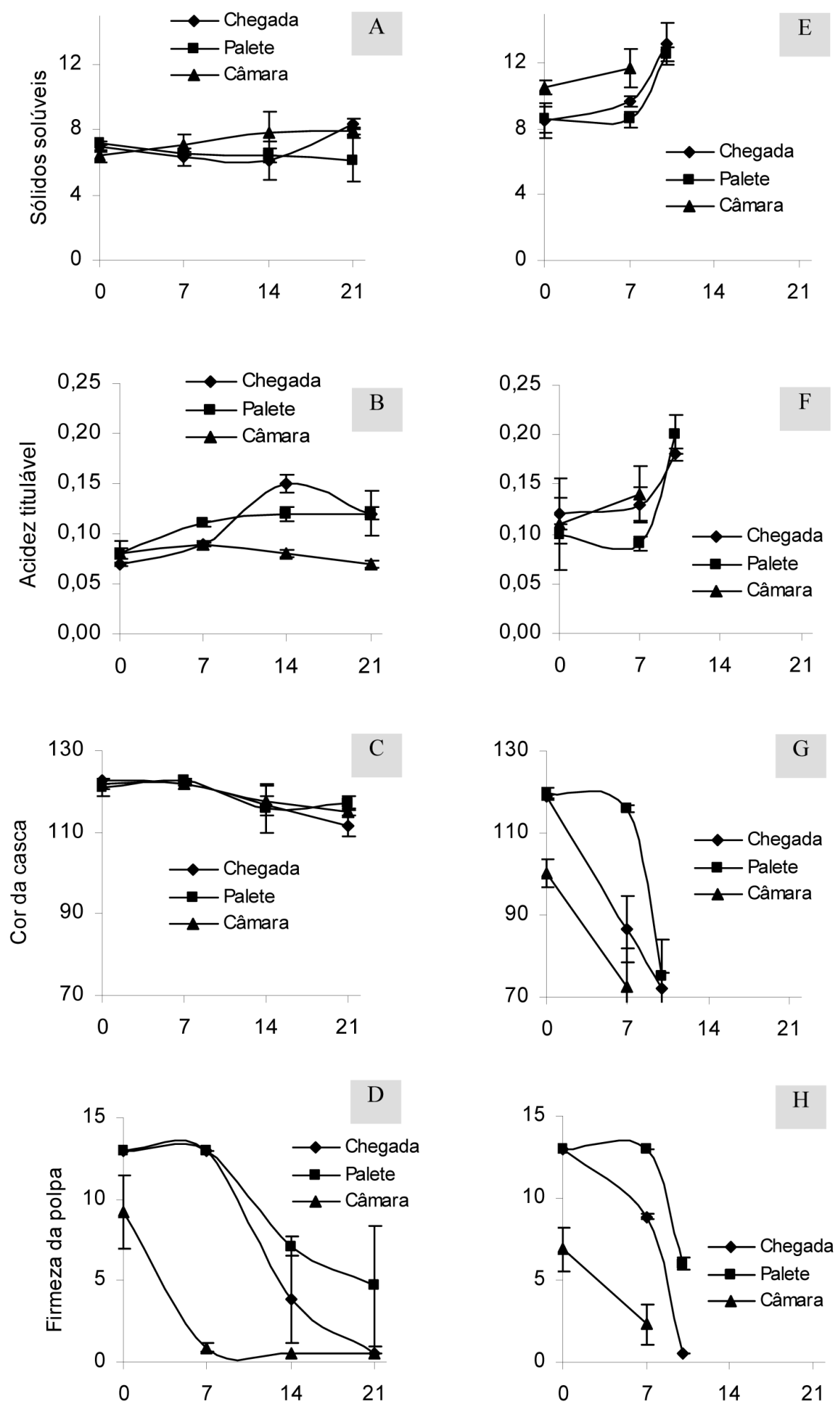

Dias de armazenamento

Figura 2. Sólidos solúveis ( ${ }^{\circ}$ Brix), acidez titulável (\% ácido citrico), cor da casca (ângulo de cor- ${ }^{\circ} \mathrm{h}$ ) e firmeza da polpa (kg) de abacates 'Fuerte' (A, B, C e D) e 'Hass' (E, F, G e H), respectivamente, oriundos de diferentes etapas do beneficiamento em packinghouse ao longo do armazenamento a $25^{\circ} \mathrm{C}$. 
Tabela 3. Efeito de produtos na incidência (\%) da antracnose em abacate 'Hass', após diferentes períodos do tratamento pós-colheita.

\begin{tabular}{lccccc}
\hline Produtos & \multicolumn{5}{c}{ Dias após o tratamento } \\
\cline { 2 - 6 } & 6 & 8 & 10 & 12 & 14 \\
\hline Testemunha & $2,8 \mathrm{a}^{1}$ & $13,3 \mathrm{a}$ & $30,0 \mathrm{a}$ & $49,2 \mathrm{a}$ & $65,0 \mathrm{a}$ \\
Azoxistrobina & $0,0 \mathrm{a}$ & $5,6 \mathrm{ab}$ & $24,7 \mathrm{ab}$ & $49,7 \mathrm{a}$ & $54,7 \mathrm{a}$ \\
Dióxido de cloro & $0,0 \mathrm{a}$ & $5,3 \mathrm{ab}$ & $13,6 \mathrm{bc}$ & $41,1 \mathrm{a}$ & $56,9 \mathrm{a}$ \\
Ecolife $^{\circledR}$ & $0,0 \mathrm{a}$ & $5,3 \mathrm{ab}$ & $21,7 \mathrm{abc}$ & $49,2 \mathrm{a}$ & $64,7 \mathrm{a}$ \\
Cloreto de benzalcônio $_{\text {Hipoclorito de Na }}$ & $0,0 \mathrm{a}$ & $2,5 \mathrm{ab}$ & $8,1 \mathrm{~cd}$ & $30,0 \mathrm{ab}$ & $46,4 \mathrm{a}$ \\
Imazalil & $0,0 \mathrm{a}$ & $5,3 \mathrm{ab}$ & $19,2 \mathrm{abc}$ & $41,4 \mathrm{a}$ & $49,4 \mathrm{a}$ \\
Procloraz & $0,0 \mathrm{a}$ & $0,0 \mathrm{~b}$ & $8,1 \mathrm{~cd}$ & $27,2 \mathrm{ab}$ & $38,1 \mathrm{ab}$ \\
Tiabendazol & $0,0 \mathrm{a}$ & $0,0 \mathrm{~b}$ & $0,0 \mathrm{~d}$ & $8,3 \mathrm{~b}$ & $10,8 \mathrm{~b}$ \\
\hline
\end{tabular}

${ }^{1}$ Valores seguidos pela mesma letra minúscula na coluna não diferem entre si, em nível de $5 \%$ pelo teste não paramétrico de comparação de múltiplas proporções.

Segundo Boshoff, Slabbert e Korsten (1995), o tratamento dos frutos com produtos a base de amônia quaternária, como é o caso de cloreto de benzalcônio (amônio quaternário catiônico) e cloro a 900 ppm, uma dose superior a empregada neste trabalho, reduziram significativamente a antracnose, de modo que o banho dos frutos com cloro nos packinghouses pode ser importante na redução das podridões.

Incidência de podridão de lasiodiplodia foi baixa, observada somente a partir do $12^{\circ}$ dia após a realização dos tratamentos. Os fungicidas imazalil e tiabendazol foram os únicos que controlaram totalmente a doença, diferindo da testemunha com $8,1 \%$ de incidência no $14^{\circ}$ dia.

Restrições crescentes a presença de resíduos químicos em alimentos têm estimulado novas alternativas de manejo em relação aos fungicidas em pós-colheita. Sob atmosfera controlada (2\% $\mathrm{O}_{2}, 10 \% \mathrm{CO}_{2}, \mathrm{a}^{\circ} \mathrm{C}$ ), o período de armazenamento pode ser estendido por até 8 semanas devido ao atraso no aparecimento da antracnose (SPALDING; REEDER, 1975). Bacillus subtilis apresentou resultados satisfatórios no controle de doenças póscolheita de abacate, com resultados semelhantes ou melhores que os fungicidas (KORSTEN, 2004). Antioxidantes utilizados como aditivos em vários alimentos atrasam o desenvolvimento da antracnose, quando utilizados nas primeiras 24 horas após a colheita, podendo ser utilizados isoladamente ou em mistura a fungicidas (PRUSKY et al., 1995).

\section{Conclusões}

O beneficiamento foi eficiente em reduzir a ocorrência da antracnose, principal podridão em abacates 'Fuerte' e 'Hass'. Injúrias mecânicas decorrentes das operações de colheita e pós-colheita não favoreceram a ocorrência das podridões quiescentes.

Frutos que receberam cera apresentaram um retardo do processo de amadurecimento, com menores alterações físicas e químicas e consequentemente um maior período de conservação a $25^{\circ} \mathrm{C}$. Entretanto, tal conservação não se manteve quando os frutos foram previamente armazenados sob refrigeração por um período de até 30 dias, devendo este período ser reduzido e mais bem estudado.

Os fungicidas procloraz e imazalil foram eficientes em controlar a antracnose do abacate.

\section{Agradecimentos}

Os autores expressam seus agradecimentos à empresa Jaguacy Brasil Comércio de Frutas Ltda., pela doação dos frutos de abacate. 


\section{Referências}

AGRINUAL. Anuário Estatístico de Agricultura Brasileira. São Paulo: FNP Consultoria e Comércio. 2008. p. 142-147.

AHMED, D. M.; AHMED, F. M.; MONGY, A. E.; AZIZ, B. A.; YOUSEF, A. R. Postharvest storage of Hass and Fuerte avocados under modified atmosphere conditions. Journal of Applied Sciences Research, Punjab, v. 3, n. 4, p. 267-274, 2007.

BEZUIDENHOUT, J. J.; KUSCHKE, E. Voorkoms en tendense van naoessiektes by Suid-Africaanse avokado's in 1982 by Rungis. South African Avocado Growers' Association Yearbooks, Duivelskloof, v. 4, p. 20-23, 1983.

BOSHOFF, M.; SLABBERT, M. J.; KORSTEN, L. Effect of detergent sanitizers on post-harvest diseases of avocado. South African Avocado Growers' Association Yearbook, Duivelskloof, v. 18, p. 96-98, 1995.

CHITARRA, M. I. F.; CHITARRA, A. B. Pós-colheita de frutos e hortaliças: fisiologia e manuseio. Lavras: ESAL-FAEPE, 1990. 310 p.

COATES, L. M.; WILLINGHAM, S. L.; PEGG, K. G.; COOKE, A.; DEAN, J.; LANGDON, P. Field and postharvest management of avocado fruit diseases. In: AUSTRALIAN AND NEW ZEALAND AVOCADO GROWERS' CONFERENCE, 1., 2001, Brisbane. Proceedings... Brisbane: Australian Avocado Growers' Federation, 2001.

COX, K. A.; MCGHIE, T. K.; WHITE, A.; WOOLF, A. B. Skin colour and pigment changes during ripening of 'Hass' avocado fruit. Postharvest Biology and Technology, Amsterdam, v. 31, n. 3, p. 287-294, 2004.

DARVAS, J. M. Stem end rot and other postharvest diseases. South African Avocado Growers' Association Yearbook, Duivelskloof, v. 2, p. 49-51, 1978.

Pre-harvest chemical control of post-harvest avocado diseases. South African Avocado Growers' Association Yearbook, Duivelskloof, v. 4, p. 71-73, 1981.

DARVAS, J. M.; KOTZE, J. M.; WEHNER, F. C. Effect of treatment after picking on the incidence of postharvest fruit disease of avocado. Phytophylactica, Pretoria, v. 22, n. 1, p. 93-96, 1990.

DONADIO, L. C. Abacate para exportação: aspectos técnicos da produção. Brasília: Frupex MAARA, 1995. $53 \mathrm{p}$.

EVERETT, K. R.; KORSTEN, L. The effect of six postharvest management regimes on ripe rots of 'Hass' avocado. Proceedings of the New Zealand Plant
Protection Society, Wellington, v. 51, p. 112-116, 1998.

FISCHER, I. H. Doenças pós-colheita em citros e caracterização da população fúngica em packinghouses e na Ceagesp. 2007. Tese (Doutorado em Agronomia) - Escola Superior de Agricultura Luiz de Queiroz. Universidade de São Paulo, Piracicaba.

HOPKIRK, G.; WHITE, A.; BEEVER, D. J. The influence of postharvest temperatures and the rate of fruit ripening on internal disorders of New Zealand 'Hass' avocado fruit. New Zealand Journal of Crop and Horticultural Science, Wellington, v. 22, n. 3, p. 305-311, 1994.

KLUGE, R. A.; JACOMINO, A. P.; OJEDA, R. M.; BRACKMANN, A. Inibição do amadurecimento de abacate com 1-metilciclopropeno. Pesquisa Agropecuária Brasileira, Brasília, v. 37, n. 7, p. 895-901, 2002.

KORSTEN, L. Biological control in Africa: can it provide a sustainable solution for control of fruit diseases? South African Journal of Botany, Africa do Sul, v. 70, n. 1, p. 128-139, 2004

KOTZÉ, J. M.; KUSCHKE, E. Control of anthracnose of avocados.Techniques to evaluate fungicides. South African Avocado Growers Association Yearbook, Duivelskloof, v. 3, p. 45-46, 1979.

LEDGER, S.; CAMPBELL, T.; BANKS, A.;ATKINSON, L.; KERNOT, I.; FULLELOVE, G. Internal quality of avocados in retail shops. Queensland: Department of Primary Industries Report, 1993. 27 p.

MAFTOONAZAD, N.; RAMASWAMY, H. S.; MOALEMIYAN, M.; KUSHALAPPA, A. C. Effect of pecin-based edible emulsion coating on charges in quality of avocado exposed to Lasiodiplodia theobromae infection. Carbohydrate Polymers, Kidlington, v. 68, n. 2, p. 341-349, 2007.

MCGUIRE, R. G. Reporting of objective color measurements. HortScience, Alexandria, v. 27, n. 12, p. 1254-1255, 1992.

MCMILLAN JUNIOR, R. T. Fungicides for disease control on avocados, limes, and mangos in Florida. Proceedings of the Florida State Horticultural Society, Winter Haven, v. 84, p. 290-294, 1971.

NORTHOVER, J.; BIGGS, A. R. Susceptibility of immature and mature sweet and sour cherries to Monilinia fructicola. Plant Disease, Saint Paul, v. 74, n. 4, p. 280-284, 1990.

OLIVEIRA, M. A.; SANTOS, C. H.; HENRIQUE, C. M.; RODRIGUES, J. D. Ceras para conservação pós-colheita de frutos de abacateiro cultivar Furte armazenados em 
temperatura ambiente. Scientia Agricola, Piracicaba, v. 57, n. 4, p. 777-780, 2000.

PALMATEER, A. J.; PLOETZ, R. C.; HARMON, P. F. Florida plant disease management guide: avocado (Persea americana). Florida: University of Florida, 2006. $10 \mathrm{p}$.

PEGG, K. G.; COATES, L. M.; KORSTEN, L.; HARDING, R. M. Foliar, fruit and soil diseases. In: WHILEY, A. W.; SCHAFFER, B.; WOLSTENHOLME, B. N. (Ed.). The avocado: botany, production and uses. Wallingford: CAB Intl. Press, 2002. p. 299-338.

PICCININ, E.; PASCHOLATI, S. F.; DI PIERO, R. M. Doenças do abacateiro. In: KIMATI, H. (Ed.). Manual de fitopatologia: doenças das plantas cultivadas. 4. ed. São Paulo: Agronômica Ceres, 2005. v. 2, p. 1-7.

POWELL, A. W. G. Shrink-wrap of avocados in combination with waxing and fungicide. South Africa Avocado Grower's Association Yearbook, Duivelskloof, v. 11, p. 39-40, 1988.

PRUSKY, D.; KEEN, N. T.; EAKS, I. Further evidence for the involvement of a preformed antifungal compound in the latency of Colletotrichum gloeosporioides on unripe avocado fruits. Physiological Plant Pathology, London, v. 22, n. 2, p. 189-198, 1983.

PRUSKY, D.; OHR, H. D.; GRECH, N.; CAMPBELL, S.; KOBILER, I.; ZAUBERMAN, G.; FUCHS, Y. Evaluation of antioxidants butylated hydroxyanisole and fungicide prochloraz for control of post-harvest anthracnose of avocado fruit during storage. Plant Disease, Saint Paul, v. 79, n. 8, p. 797-800, 1995.
QUEZADA, A. G.; ROJAS, S. H. V.; TELIZ, O. D. First report of the anamorph of Glomerella acutata causing anthracnose on avocado fruits in Mexico. Plant Disease, Saint Paul, v. 91, n. 9, p. 1200, 2007.

SANCHES, J.; DURIGAN, J. F.; DURIGAN, M. F. B. Aplicação de danos mecânicos em abacates e seus efeitos na qualidade dos frutos. Engenharia Agrícola, Jaboticabal, v. 28, n. 1, p. 164-175, 2008.

SHARMA, R. L.; KAUL, J. L. Susceptibility of apples to brown rot in relation to quantitative characters. Indian Phytopathology, Nova Delhi, v. 43, n. 1, p. 113-115, 1988.

SOUZA, D. C. Progresso temporal e padrão espacial de epidemias da podridão parda do pessegueiro. 2007. Dissertação (Mestrado em Agronomia) - Escola Superior de Agricultura Luiz de Queiroz. Universidade de São Paulo, Piracicaba.

SPALDING, D. H.; REEDER, W. F. Low oxygen high-carbon dioxide controlled atmosphere storage for control of anthracnose and chilling injury of avocados. Phytopathology, Saint Paul, v. 65, n. 4, p. 458-560, 1975.

WILLINGHAM, S. L.; PEGG, K. G.; ANDERSON, J. M.; COOKE, A. W.; DENA, F. R.; GIBLIN, F. R.; COATES, L. M. Effects of rootstock and nitrogen fertilizer on postharvest anthracnose development in Hass avocado. Australasian Plant Pathology, Collingwood, v. 35, n. 6, p. 619-629, 2006.

ZAR, J. H. Biostatistical analyis. New Jersey: PrenticeHall, 1999. 663 p. 